\title{
BMJ open The mortality and cancer experience of New Zealand Vietnam war veterans: a cohort study
}

\author{
David McBride, ${ }^{1,2}$ Brian Cox, ${ }^{3}$ John Broughton, ${ }^{4}$ Darryl Tong ${ }^{5}$
}

To cite: McBride D, Cox B, Broughton J, et al. The mortality and cancer experience of New Zealand Vietnam war veterans: a cohort study. BMJ Open 2013;3:e003379. doi:10.1136/bmjopen-2013003379

- Prepublication history for this paper is available online. To view these files please visit the journal online (http://dx.doi.org/10.1136/ bmjopen-2013-003379).

Received 10 June 2013 Accepted 11 July 2013

\author{
${ }^{1}$ Department of Preventive \\ and Social Medicine, \\ University of Otago, Dunedin, \\ New Zealand \\ ${ }^{2}$ Centre for Military and \\ Veterans Health, University of \\ Queensland, Herston, \\ Queensland, Australia \\ ${ }^{3}$ Hugh Adam Cancer \\ Epidemiology Unit, University \\ of Otago, Dunedin, New \\ Zealand \\ ${ }^{4}$ Ngai Tahu Māori Health \\ Research Unit, University of \\ Otago, Dunedin, New Zealand \\ ${ }^{5}$ Department of Oral \\ Diagnostic and Surgical \\ Sciences, University of \\ Otago, Dunedin, New Zealand
}

Correspondence to Dr David McBride; david.mcbride@otago.ac.nz

\section{ABSTRACT}

Objectives: The aim was to observe the patterns of mortality and cancer incidence in New Zealand Vietnam veterans. The objectives were to assess whether the patterns of disease observed were consistent with those associated with military service in Vietnam, and similar to the patterns identified in other groups of Vietnam veterans.

Design: A historical cohort study.

Setting: Veterans, identified from service records, with Vietnam service between 1964 and 1972.

Participants: Of the 3322 survivors of Vietnam service, we followed up 2783 (84\%).

Outcome measures: Standardised mortality and incidence ratios (SMRs and SIRs, respectively) were calculated based on the number of deaths and cancer registrations observed, those expected being based on New Zealand national rates.

Results: All cause mortality was significantly reduced (SMR $0.85,95 \% \mathrm{Cl} 0.77$ to 0.94 ) and cancer incidence non-significantly increased (SIR 1.06, 95\% Cl 0.97 to 1.16). The risk of mortality from cancers of the head and neck (SMR 2.20, $95 \% \mathrm{Cl} 1.09$ to 3.93); oral cavity pharynx and larynx (SMR 2.13, 95\% Cl 1.06 to 3.81) and the incidence of chronic lymphatic leukaemia (CLL) (SIR $1.91,95 \% \mathrm{Cl} 1.04$ to 3.20 ) were, however, significantly increased. Other lymphohaematopoietic disorders, specifically multiple myeloma and Hodgkin disease, showed non-significant mortality excesses, reflected by a similar increase in incidence.

Conclusions: Service in the Vietnam war was associated with defoliant herbicide exposure, including 2,4,5trichlorophenoxyacetic acid, 2,4-dichlorophenoxyacetic acid, picloram and cacodylic acid. Subsequent reviews of mechanistic, animal and epidemiological evidence led to certain conditions being deemed compensable. The pattern of mortality and cancer incidence is not at odds with the list of compensable conditions and consistent with that found in Australian veterans serving in the same area of Vietnam, but also consistent with smoking and the healthy soldier effect. In common with the Australian experience, this is the only veterans group to show a significant excess of CLL.

\section{INTRODUCTION}

Between 1964 and 1975 nearly 3400 New Zealand military personnel served in the

\section{ARTICLE SUMMARY}

Article focus

- Service in the Vietnam war was characterised by defoliant herbicide exposure, including 2,4,5-trichlorophenoxyacetic acid, 2,4-dichlorophenoxyacetic acid, picloram and cacodylic acid. The Institute of Medicine of the US National Academy of Sciences has carried out cumulative reviews of the mechanistic, animal and epidemiological evidence for the relationship between herbicide exposure and health and compiled lists of conditions associated with Vietnam service, adopted as 'presumptive lists' compensable by Veterans Affairs New Zealand.

- Those in the cancer 'sufficient evidence' list are softtissue sarcoma (including heart); non-Hodgkin lymphoma (NHL); chronic lymphocytic leukaemia (CLL) (including hairy cell leukaemia and other chronic B-cell leukemias) and Hodgkin disease, those on the 'limited or suggestive' list being laryngeal cancer; cancer of the lung, bronchus or trachea; prostate cancer and multiple myeloma.

- This report examines whether the mortality and cancer experience of New Zealand veterans is consistent with Vietnam service and the lists of conditions accepted as being compensable.

\section{Key messages}

- CLL is on the 'sufficient' list largely because of an increased incidence in the farming occupation and a similarity to non-Hodgkin lymphoma in that both are due to malignant transformation of $B$ progenitor cells.

- Our results, along with those of an earlier Australian study, provide epidemiological evidence of an increased risk of CLL in veterans.

Strengths and limitations of this study

- The follow-up of $83 \%$ would tend to minimise bias in the direction of underestimating disease risks.

- In common with other studies, we do not have exposure data, but the similarity to the Australian veterans experience suggests an ecological effect.

- We also have no information concerning confounding by smoking and alcohol consumption, known to be associated with head and neck cancers.

Republic of Vietnam. The majority of the force was involved in combat operations, from 1966 onwards integrated with an 
Australian New Zealand Army Corps (ANZAC) Battalion deployed to the East of Saigon, now Ho Chi Minh City, in the Nui Dat area of Phuoc Tuy province, now Bà Rịa city in Bà Rịa-Vũng Tàu province. At its peak in 1968, it represented a force of 543 personnel. Smaller numbers served in the New Zealand Medical Services team based in Binh Dinh province and training teams in Khánh Hóa and Châu Đốc.

Chemical exposure was a significant feature of this war. Tactical defoliant herbicide sprays, distributed in 55 gallon drums with a colour stripe classification, led to the hallmark 'rainbow agent' exposure. Agents Pink and Green contained esters of 2,4,5-trichlorophenoxyacetic acid (2,4,5-T) and Agents Purple and Orange esters of 2,4,5-T and 2,4-dichlorophenoxyacetic acid (2,4-D). $2,4,5-\mathrm{T}$ was contaminated, to a greater or lesser extent, with 2,3,7,8-tetrachlorodibenzo-para-dioxin (TCDD or simply 'dioxin'). Those herbicides not contaminated with dioxin included Agent White, a mixture of 2,4-D and picloram and finally Agent Blue, a formulation of cacodylic acid (dimethyl arsenic acid or DMA) and its salts. Agent Orange, with an estimated $45677937 \mathrm{~L}$ sprayed, ${ }^{1}$ has come to epitomise the environmental worries of Vietnam veterans regarding their service.

Subsequent concerns about the toxicity of these substances and the relationship with health effects led the US Department of Veterans Affairs and The Institute of Medicine of the US National Academy of Sciences (IOM) to conduct a biennial and cumulative epidemiological review of herbicide exposure. The evidence is not based on causality but on the strength of epidemiological evidence associating herbicide exposure with health. The IOM report classifies the evidence in support of a relationship as 'sufficient', 'limited or suggestive', or 'inadequate or insufficient'. Those in the cancer 'sufficient evidence' list in the 2010 update $^{2}$ are soft-tissue sarcoma (including heart); non-Hodgkin lymphoma (NHL); chronic lymphocytic leukaemia (CLL) (including hairy cell leukaemia and other chronic B-cell leukemias) and Hodgkin disease. Those on the 'limited or suggestive' list are laryngeal cancer; cancer of the lung, bronchus or trachea; prostate cancer and multiple myeloma. The evidence reviewed comes from biological plausibility, animal studies, studies of the incidence of cancer in people with occupational exposure to herbicides and a number of Vietnam veterans' studies. The latter studies have been based on cohorts of American, Australian and Korean Veterans. This is the first cohort study of New Zealand Vietnam War Veterans, undertaken to assess whether health outcomes were consistent with those reported by the IOM as being due to Vietnam service.

\section{METHODS}

Design

This is a cohort study of New Zealand Vietnam veterans who served in Vietnam between 1964 and 1975.

\section{Cohort enumeration}

The original nominal roll for the cohort was compiled in 1972 from pay records and formed the basis of the Veterans Affairs New Zealand (VANZ) Vietnam veterans' database, a cohort of 3394 men and women. VANZ administers all aspects of war service entitlements, including war pensions, and the service list is now regarded as being complete.

Of this cohort of 3394 service people, 37 died during the war. The remaining 3357 were followed up through searches based on the National Health Index number linking individuals to health data maintained by the New Zealand Ministry of Health (MoH). No match was found for 791 veterans, but searches on the electoral rolls from 1993 to 2009 provided details of 252 . We had to exclude 539 individuals who we could not match. Of these, 336 had an overseas address and 203 were lost to follow-up. We also had to exclude 34 men who had a date of death listed by VANZ but no official record on the MoH collections and the 32 women who formed too small a subgroup for analysis. Follow-up started on 1 January 1988, the first date that data is held electronically on the Mortality Collection database. The end of follow-up was 31 December 2008, the last date that mortality data were available. The Mortality Collection provided the underlying cause of death for all deaths identified. Prior to coding and entry on the Mortality Collection database all the deaths registered by Births, Deaths and Marriages New Zealand are subject to verification. The official underlying cause of death recorded is determined after compiling data from a number of additional sources including traffic accident reports, Coroners' inquiries, hospital diagnoses, pathology records and cancer registry entries. The mortality statistics are compiled according to the year the death is registered: deaths before 2000 are recorded in ICD-9-CM-A and have not been mapped forward to ICD-10-AM.

\section{Exposure information}

Methodologically, the weakest aspect of the epidemiological studies of Vietnam veterans has been exposure assessment. The simplest approach is ecological, based on Vietnam service, geographical area and branch of service (Ref. 3, p.270). As regards service, the New Zealand records are regarded as complete. Defoliation missions are recorded as being flown in the geographical area (Ref. 3, p.98) and by far the largest New Zealand contribution was of combat troops, artillerymen and infantry soldiers, acknowledged to be at greater risk of herbicide exposure. The antimalarial drug of choice was dapsone, with aerial spraying of organochlorine pesticides to control mosquitoes, but unfortunately the exposure doses of both cannot easily be determined.

\section{Statistical analysis}

We used the cohort analysis methods described by Breslow and Day, ${ }^{4}$ calculating the person-years of follow-up for the cohort through each 5-year age 
category from 30 or more years of age for each of the 5-time periods, 1988-1990, 1991-1995, 1996-2000, 2001-2005 and 2006-2008. Standardised mortality ratios (SMRs) and standardised incidence ratios (SIRs) were then computed based on the number of deaths and cancer registrations observed, the expected numbers being based on New Zealand national rates. The 95\% CIs were estimated using the Poisson distribution.

\section{RESULTS}

The cohort status is shown in table 1 .

Of the 3322 men of the original cohort of survivors of the Vietnam War, 2783 men $(83.8 \%)$ were matched and considered to be alive at the beginning of 1988. Of the 539 records not matched, $57.1 \%$ had no address and 29.7\% had an overseas address listed by VANZ. In addition, VANZ listed a date of death for 34 men $(6.3 \%)$ whose death was not confirmed by the MoH. As these deaths were unconfirmed by the official New Zealand records, and no cause of death was listed, the death information recorded by VANZ was not used. Of those without an overseas address $89 \%$ were traced, either by the $\mathrm{MoH}$ or by the research team using electoral rolls from 1993 to 2009.

The deaths of 407 members of the cohort were recorded in New Zealand during this period. The SMRs for various causes of death are shown in table 2. The SMR for all causes of death was 0.85 (95\% CI 0.77 to 0.94) suggesting lower overall mortality in the cohort. There were $159(39.1 \%)$ 'all cancer' deaths with a significantly higher SMR for cancers of the head and neck (SMR 2.20, 95\% CI 1.09 to 3.93), in particular cancers of the oral cavity, pharynx and larynx (SMR 2.13, 95\% CI 1.06 to 3.81). There were more deaths from multiple myeloma and Hodgkin disease than expected, but based on small numbers the SMRs were not significantly raised.
The SIRs for cancer incidence over the period are shown in table 3 . We found no statistically significant excess of cancer incidence for the 1988-2008 time period ( $\mathrm{SIR}=1.06,95 \%$ CI 0.97 to 1.16 ). The incidence of CLL was, however, significantly higher. The SIRs for cancer of the prostate, lung, larynx, multiple myeloma, Hodgkin disease, non-lymphoid leukaemia and bone and cartilage were increased, but not significantly so.

\section{DISCUSSION}

All cause mortality was significantly reduced by $15 \%$ in this group, with a lesser and non-significant deficit in all cancer deaths and no decrease in all cancer incidence. Specific cancer sites demonstrated an increase in risk, with twice the risk of mortality from head and neck cancers. There was also a twofold and significantly increased incidence of CLL. Other lymphohaematopoietic disorders, specifically multiple myeloma and Hodgkin disease, showed non-significant mortality excesses, reflected by a similar increase in incidence.

One of the strengths of the study was that the New Zealand forces served with the Australian Army in one geographical area, in contrast to USA cohorts which proved more difficult to enumerate and locate geographically. ${ }^{3}$ A further strength was the excellent follow-up in terms of the $84 \%$ of the cohort that we are able to trace, which would tend to minimise bias (in the direction of underestimating disease risks) in the results. We did have weaknesses in that we were only able to trace deaths in the decades from 1988 onwards, however, we would in any case have lagged exposure by 10-20 years to account for the latent period of cancer, thus excluding earlier deaths.

The relatively small size of the cohort limited the power of the study, the other main weaknesses being the absence of information on confounders including

Table 1 Cohort information and follow-up

\begin{tabular}{|c|c|c|c|c|}
\hline \multirow[b]{2}{*}{ Available information } & \multicolumn{2}{|l|}{ Male } & \multicolumn{2}{|l|}{ Female } \\
\hline & Number & Per cent & Number & Per cent \\
\hline Surname & 3361 & 100.0 & 33 & 100.0 \\
\hline An additional surname & 2 & 0.1 & 2 & 0.1 \\
\hline Forename initials only & 7 & 2.3 & 0 & 0.0 \\
\hline An alias available & 25 & 0.7 & 2 & 6.1 \\
\hline Date of birth not available & 52 & 1.6 & 0 & 0.0 \\
\hline Alternative date of birth & 5 & 0.1 & 0 & 0.0 \\
\hline No address & 1205 & 35.9 & 12 & 36.4 \\
\hline Overseas address & 336 & 10.0 & 3 & 9.1 \\
\hline Died in Vietnam service & 36 & 1.1 & 1 & 3.0 \\
\hline Died after Vietnam war and before 1988 & 3 & 0.1 & 0 & 0.0 \\
\hline Male survivors of Vietnam service & 3322 & 98.8 & & \\
\hline Men matched by Ministry of Health & 2531 & & & \\
\hline Men matched with electoral roll & 252 & & & \\
\hline Men followed up & 2783 & 83.8 & & \\
\hline Not matched & 539 & 16.2 & & \\
\hline Unconfirmed date of death & 34 & 6.3 & & \\
\hline
\end{tabular}


Table 2 Standardised mortality ratios for the 1988-2008 time period

\begin{tabular}{|c|c|c|c|c|}
\hline Cause of death & Observed & Expected & SMR & $95 \% \mathrm{Cl}^{*}$ \\
\hline All deaths & 407 & 478.1 & 0.85 & 0.77 to 0.94 \\
\hline Coronary heart disease & 104 & 123.7 & 0.84 & 0.69 to 1.02 \\
\hline Respiratory disease (not COPD) & 12 & 29.8 & 0.40 & 0.21 to 0.70 \\
\hline COPD & 18 & 23.2 & 0.78 & 0.46 to 1.23 \\
\hline Infectious disease (excluding AIDS) & 3 & 4.0 & 0.75 & 0.15 to 2.22 \\
\hline Accidents and suicide & 27 & 31.9 & 0.85 & 0.56 to 1.23 \\
\hline Accidents & 11 & 20.8 & 0.53 & 0.26 to 0.95 \\
\hline Suicide & 16 & 11.2 & 1.43 & 0.82 to 2.33 \\
\hline All cancer deaths & 159 & 173.5 & 0.92 & 0.78 to 1.07 \\
\hline All other causes of death & 84 & 92.0 & 0.91 & 0.73 to 1.13 \\
\hline \multicolumn{5}{|l|}{ Select cancer sites } \\
\hline Prostate cancer & 13 & 12.6 & 1.03 & 0.55 to 1.76 \\
\hline Lung cancer & 50 & 43.6 & 1.15 & 0.85 to 1.51 \\
\hline Stomach & 9 & 7.1 & 1.27 & 0.58 to 2.42 \\
\hline Pancreas & 5 & 7.5 & 0.67 & 0.22 to 1.56 \\
\hline Colorectal cancer & 20 & 19.2 & 1.04 & 0.64 to 1.61 \\
\hline Head and neck* & 11 & 5.0 & 2.20 & 1.09 to 3.93 \\
\hline Oral cavity, pharynx and larynx $†$ & 11 & 5.2 & 2.13 & 1.06 to 3.81 \\
\hline Larynx & 2 & 1.0 & 2.00 & 0.23 to 7.39 \\
\hline Melanoma & 4 & 7.2 & 0.56 & 0.15 to 1.42 \\
\hline Multiple myeloma & 5 & 3.2 & 1.58 & 0.51 to 3.69 \\
\hline Hodgkin disease & 1 & 0.4 & 2.30 & 0.03 to 12.8 \\
\hline NHL & 3 & 7.0 & 0.43 & 0.09 to 1.25 \\
\hline All leukaemia & 4 & 5.6 & 0.71 & 0.19 to 1.83 \\
\hline Non-lymphoid leukaemia & 3 & 3.8 & 0.78 & 0.16 to 2.28 \\
\hline Lymphoid leukaemia & 1 & 1.8 & 0.57 & 0.01 to 3.16 \\
\hline All other cancers & 34 & 54.9 & 0.62 & 0.43 to 0.87 \\
\hline
\end{tabular}

COPD, chronic obstructive pulmonary disease;NHL, non-Hodgkin lymphoma; SMR, standardised mortality ratios.

*Excludes cancer of the larynx or oesophagus.

†Head and neck without cancer of the lip, sinus cavities or salivary glands, but includes cancer of the larynx.

$\ddagger$ All cancer except; lung, prostate, stomach, pancreas, colon and rectum, oral cavity, pharynx, larynx, melanoma, multiple myeloma, Hodgkin disease, non-Hodgkin lymphoma, and all leukaemia.

ethnicity, alcohol consumption, smoking status and environmental exposure. We do not know how many cohort members might have identified themselves as being of Māori ethnicity, but the New Zealand Defence force has always been able to recruit proportionately more Maori than are found in the general population. Māori are known to have poorer health than those of European origin, ${ }^{5}$ however, there was little evidence of poorer overall health in Vietnam veterans during the follow-up period, at least in terms of increased mortality and cancer incidence. Smoking would be expected to cause (in those sites presented here) an increased risk of oral and lung cancers, with alcohol being an additional cause of cancers of the oral cavity, pharynx and larynx.

We are, of course, limited by the fact that we do not have data on environmental exposures. The Nui Dat area lay in US Military Region 3, and approximately $20 \mathrm{~km}$ distant from the Rung Sat special zone, known to have been heavily sprayed. ${ }^{3}$ Infantry soldiers were more likely to be exposed because they more often engaged with the enemy and were, therefore, more likely to enter sprayed areas. They were also potentially exposed to other agents such as dapsone and insecticides. The clustering of troops by geographic area and combat experience may reduce misclassification bias to environmental exposures, but the potential for such bias remains high.

Interpretation of the results requires consideration of bias in terms of the healthy worker effect, in this case the "healthy soldier effect. ${ }^{6}$ The application and selection process for military service, and further selection prior to operational deployment, results in a cohort which has lower disease incidence and mortality than the general population. The effect is evident in this cohort and would be reduced by the selection of a serving but non-deployed comparison group. At the time of the study, this would have required manual selection from paper files, a process which was not logistically possible.

The most comprehensive body of comparative evidence comes from American Vietnam veterans studies, the largest of which is the 'Vietnam Experiences Study' (VES). ${ }^{7}$ The base for this cohort was 48513 individuals randomly selected from service records. After applying inclusion criteria and excluding those who had died in-service, it yielded 9324 Vietnam veterans and 8989 in a non-Vietnam cohort. There was no overall increase in 
Table 3 Standardised incidence ratios of cancer for the 1988-2008 time period

\begin{tabular}{lcccc}
\hline Cancer site & Observed & Expected & SIR & 95\% CI \\
\hline All cancer & 458 & 431 & 1.06 & 0.97 to 1.16 \\
Prostate cancer & 136 & 116.2 & 1.17 & 0.98 to 1.39 \\
Lung cancer & 58 & 51.1 & 0.82 & 0.38 to 1.47 \\
Stomach & 9 & 1.56 \\
Pancreas & 6 & 8.9 & 0.72 & 0.26 to 1.57 \\
Colorectal cancer & 63 & 66.6 & 0.95 & 0.73 to 1.21 \\
Head and neck* & 19 & 14.2 & 1.34 & 0.81 to 2.09 \\
Oral cavity, pharynx and larynx† & 18 & 13.7 & 1.32 & 0.78 to 2.08 \\
Larynx & 5 & 4.2 & 1.18 & 0.38 to 2.77 \\
Melanoma & 33 & 44.8 & 0.74 & 0.51 to 1.04 \\
Multiple myeloma & 9 & 6 & 1.51 & 0.69 to 2.86 \\
Hodgkin disease & 3 & 1.4 & 2.08 & 0.42 to 6.09 \\
NHL & 14 & 16.6 & 0.85 & 0.46 to 1.42 \\
All leukaemia & 21 & 12.8 & 1.64 & 1.02 to 2.51 \\
Non-lymphoid leukaemia & 7 & 5.4 & 1.29 & 0.52 to 2.66 \\
Lymphoid leukaemia & 14 & 7.3 & 1.91 & 1.04 to 3.20 \\
Connective and soft tissue & 3 & 2.9 & 1.04 & 0.21 to 3.04 \\
Bone and cartilage & 2 & 0.7 & 2.78 & 0.31 to 10.0 \\
All other cancers $\ddagger$ & 82 & 78.6 & 1.04 & 0.83 to 1.29 \\
\hline
\end{tabular}

$\mathrm{NHL}$, non-Hodgkin lymphoma; SIR, standardised incidence ratios.

${ }^{*}$ Excludes cancer of the larynx or oesophagus.

tHead and neck without cancer of the lip, sinus cavities, or salivary glands but includes cancer of the larynx.

$\ddagger$ All cancer except; lung, prostate, stomach, pancreas, olon and rectum, oral cavity, pharynx, larynx, melanoma, multiple myeloma, Hodgkin disease, non-Hodgkin lymphoma, and all leukaemia (includes connective and soft tissue).

mortality when comparing these two groups, and both groups of veterans showed the healthy soldier effect in SMR analyses.

The other relevant epidemiological study is the Air Force Health Study of USA Air Force personnel who took part in operation 'Ranch Hand' and deployed herbicides including Agent Orange. This group originally consisted of 1261 Ranch Hand veterans who were initially matched to 19080 comparison Air Force personnel who were followed up for mortality and morbidity. ${ }^{8}$ The mortality follow-up ceased in 2002, by which time there was a statistically increased risk of all causes mortality for all participants (relative risk (RR) 1.3, 95\% CI 1.0 to 1.3) and a statistically increased risk of death from circulatory diseases $(\mathrm{RR}=1.7,95 \% \mathrm{CI} 1.2$ to 2.4$){ }^{9}$

The most similar comparison group is the Australian Vietnam veterans cohort, a much larger group of 59179 individuals, consisting of 23\% Navy, 69\% Army and 8\% Air Force personnel $^{10}{ }^{11}$ (http://www.dva.gov.au/aboutDVA/ publications/health_research/vietnam_vets/Pages/index. aspx). The main points of comparison between the two are a similar healthy soldier effect, with significantly fewer deaths from all causes in both cohorts but a contrast in the $6 \%$ significant excess of all cancer deaths in the Australian cohort, cancer also being the single most common cause of death. There are proportionately, though not significantly, more deaths from suicide in New Zealand veterans. Lung cancer contributed the greatest burden of deaths in the New Zealand and Australian cohorts, with excesses of $15 \%$ and $18 \%$, respectively, only the latter being significant. Other significant causes of cancer-related deaths in the
Australian cohort, all head and neck along with oral cavity, pharyngeal and laryngeal cancers, were similar to those found in New Zealand veterans. Cancer incidence showed a non-significant overall excess of $6 \%$ in the New Zealand cohort, the excess of $15 \%$ being significant for Australian veterans. The SIR for CLL was $1.68,95 \%$ CI 1.18 to 2.19 in Australian Army Vietnam veterans (Ref. 11, p.91) less than the SIR of $1.91,95 \%$ CI 1.04 to 3.20 which we found.

As they operated in the same area, the exposures of New Zealand and Australian veterans would have been the same, and the patterns of disease are similar. The mortality and morbidity experience in these cohorts are neither at odds with the IOM classification nor the 'presumptive list' adopted as being compensable by VANZ. Further work should include the selection a serving, but non-deployed, comparison group, which will reduce the healthy soldier effect. We hope to do this and also to collect information on possible confounders (ethnicity, smoking and alcohol consumption) in the surviving cohort members.

In summary, we have identified a risk of CLL that is significantly higher in New Zealand Vietnam veterans than the general population, confirming the similar result found for Australian veterans. CLL was first classified on the 'sufficient' list by the IOM in 2002 (Ref. 12, p.377) on the basis of an increased risk in farming populations exposed to herbicides and a mechanistic similarity to non-Hodgkin lymphoma in that both are due to malignant transformation of $\mathrm{B}$ progenitor cells. The Australian and New Zealand veterans groups are, however, the only ones to show this increased risk. 
Acknowledgements The authors would like to acknowledge Captain Conrad Flinkenberg for his foresight in compiling the original cohort from pay records, and the New Zealand Ex-Vietnam Services Association for their encouragement. They are grateful to the staff of Veterans Affairs New Zealand, particularly Corina Herewini, for their invaluable help in updating and formatting the service records, and for the assistance of the analytical services staff at the Ministry of Health.

Contributors DM developed the study proposal, wrote the grant application, assisted in interpreting the results and wrote the drafts. BC analysed the data and wrote the initial report. JB advised on the cultural aspects of the proposal, assisted in study design, with the interpretation of the results and helped to write the drafts. DT assisted in study design and interpretation of the results and helped to write the drafts.

Funding The study was funded by the New Zealand War Pensions Medical Research Trust Fund. BC was funded by the Director's Cancer Research Trust. Competing interests None.

Ethics approval Ethical approval was given by the New Zealand Multi-regional Ethics Committee: the Ngäi Tahu Research Consultation Committee also gave us a perspective on the Māori health aspects of our proposal.

Provenance and peer review Not commissioned; externally peer reviewed.

Data sharing statement Additional tables can be requested from the corresponding author.

Open Access This is an Open Access article distributed in accordance with the Creative Commons Attribution Non Commercial (CC BY-NC 3.0) license, which permits others to distribute, remix, adapt, build upon this work noncommercially, and license their derivative works on different terms, provided the original work is properly cited and the use is non-commercial. See: http:// creativecommons.org/licenses/by-nc/3.0/

\section{REFERENCES}

1. Stellman JM, Stellman SD, Christian R, et al. The extent and patterns of usage of Agent Orange and other herbicides in Vietnam. Nature 2003;422:681-7.

2. Committee to Review the Health Effects in Vietnam Veterans of Exposure to Herbicides. Veterans and Agent Orange: Update 2010. Washington, DC: The National Academies Press, 2012.

3. Committee to Review the Health Effects in Vietnam Veterans of Exposure to Herbicides. Veterans and Agent Orange: Update 1994. Washington, DC: The National Academies Press, 1994.

4. Breslow NE, Day NE. Statistical methods in cancer research volume II-the design and analysis of cohort studies. Lyon: International Agency for Research on Cancer, 1987.

5. Bramley D, Hebert P, Tuzzio L, et al. Disparities in indigenous health: a cross-country comparison between New Zealand and the United States. Am J Public Health 2005;95:844-50.

6. Waller M, McGuire ACL. Changes over time in the healthy soldier effect. Popul Health Metrics 2011;9:1-9.

7. Boyle CA. Postservice mortality among Vietnam veterans. The Centers for Disease Control Vietnam Experience Study. JAMA 1987;257:790-5.

8. Michalek JE, Ketchum NS, Akhtar FZ. Postservice mortality of us air force veterans occupationally exposed to herbicides in Vietnam: 15-year follow-up. Am J Epidemiol 1998;148:786-92.

9. Ketchum NS, Michalek JE. Postservice mortality of Air Force veterans occupationally exposed to herbicides during the Vietnam War: 20-Year follow-up results. Mil Med 2005;170:406-13.

10. Wilson EJ, Horsley KW, Van der Hoek R. The Third Australian Vietnam Veterans Mortality Study 2005. Canberra: Department of Veteran's Affairs, 2005

11. Wilson EJ, Horsley KW, Van der Hoek R. Cancer Incidence in Australian Vietnam Veterans Study 2005. Canberra: Department of Veteran's Affairs, 2005

12. Committee to Review the Health Effects in Vietnam Veterans of Exposure to Herbicides. Veterans and Agent Orange: update 2002. Washington, DC: The National Academies Press, 2003 